\title{
Net gmotzt ...
}

_ Bei uns im Schwäbischen gibt es das Sprichwort „Net gmotzt isch globt gnug“. Vielleicht war das für viele unserer Leser ein Grund, nicht an der Umfrage Ende 2012 teilzunehmen. Wir wissen es nicht. Doch 77 Leser haben für Klarheit gesorgt und uns geantwortet. Danke!

_ Die Umfrage ist nicht repräsentativ, und ein Trend lässt sich davon auch nicht ableiten, dennoch ist das Feedback für uns wertvoll. Hier die Ergebnisse: 32 Prozent der Umfrageteilnehmer gefällt physiopraxis insgesamt sehr gut, 53 Prozent gut. Am beliebtesten sind die therapeutischen Themen, insbesondere der „Fall für Vier“ kommt gut an.

_ Unsere Leser schätzen an physiopraxis die Vielseitigkeit, die objektive Berichterstattung, die Fachkompetenz, den hohen Praxisbezug und das schöne Design der Zeitschrift. Ein Therapeut merkte an, ihm gefalle es, einen

\section{physiopraxis-Leserumfrage}

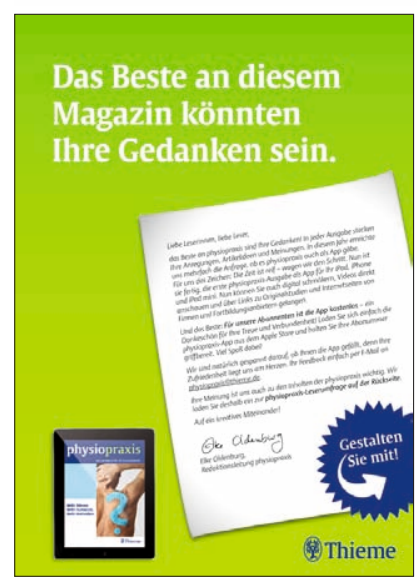
Überblick darüber zu bekommen, was die Berufsgruppe insgesamt interessiert. Eine Therapeutin fühlt sich durch physiopraxis angeregt, ihre Arbeit zu hinterfragen, und bleibe so fit.

_ Manche wünschen sich noch mehr praktische Behandlungsideen, andere mehr wissenschaftliche Themen und wissenschaftliche Tiefe und einige mehr Berufspolitik. Die Interessen unserer Leser sind sehr unterschiedlich, und wir geben alles, um auch weiterhin den Spagat zu meistern. Besonders gefreut hat uns die Rückmeldung einer Therapeutin, wir seien „kurz, prägnant, informativ und so geschrieben, dass man um 22 Uhr noch ein fachfremdes Gebiet versteht“. Genau das ist der Anspruch, den wir an unsere Texte stellen.

_ Ein Leser bittet um eine Erläuterung, warum sein Abo immer mehr Werbung enthalte. Hierfür gibt es drei gute Gründe: Die Firmen finden physiopraxis attraktiv und wollen darin werben. Die Anzeigen informieren unsere Leser über Produkte, Dienstleistungen und Fortbildungen im Bereich der Physiotherapie. Zudem ermöglichen uns diese Einnahmen, den Abopreis und die Qualität der Zeitschrift seit Jahren annähernd stabil zu halten. Also ein fruchtbares Miteinander. Herzlich, Ihre
Im November wollten wir von Ihnen wissen, wie Ihnen physiopraxis gefällt und was wir besser machen können.

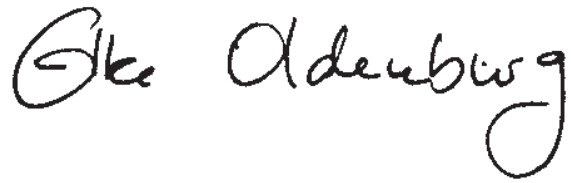

